\title{
An Evaluation of the Leonard Cheshire Zimbabwe Trust (LCZT) Pilot Inclusive Education Programme in Zimbabwe: the Perspective of Teachers and Heads. (PART A)
}

\author{
${ }^{1}$ Lincoln Hlatywayo, ${ }^{2}$ Zano Augustine Muranda \\ (DEd Candidate, MSc, MEd, BSc, Diploma, Certificate) \\ Senior Lecturer: Disability Studies and Special Needs Education, Zimbabwe Open University \\ Lecturer: Educational Management, Zimbabwe Open University
}

\begin{abstract}
The focus of this study was on evaluating the progress of the pilot project carried out by Leonard Cheshire Zimbabwe Trust (LCZT) in partnership with the Ministry of Education, Sport, Arts and Culture on Inclusive Education in the Zimbabwean primary schools. The descriptive survey design underpinned the study. The research field were the three primary schools where Leornard Cheshire Zimbabwe Trust was implementing an inclusive education pilot study for learners with disabilities. Respondents were five teachers purposively chosen from each of the three schools. The three school heads automatically became respondents to make a total representative sample of 18. Questionnaires were used to collect data. The results have shown promising results for the country. A good number of children who previously were not attending school are now enrolled. LCZT has also managed to train teachers, heads and parents on inclusive education and strategies such as those recommended by UNESCO (1999) were being implemented. However the results also revealed that most teachers had no qualifications in special education and had problems handling the disabled children. The lack of resources is also hampering implementation. The study recommended for the continuous training of regular teachers and other professionals who deal with children with disabilities is to equip them with the teaching methods appropriate for children with disabilities and type of interventions to use. Such knowledge creates positive attitudes towards children with disabilities. It was also recommended that accessible and flexible curricula be designed as these would serve as key to creating inclusive education.
\end{abstract}

Keywords: children with disabilities, inclusive education, Leornard Cheshire Zimbabwe Trust (LCZT), Regular/mainstream class

\section{Introduction}

Zimbabwe is a member of the United Nations and has agreed to recognize the rights of People with Disabilities (PWD) through the declarations passed by the United Nations Human Rights including the ratification of the United Nations Convention on the Rights of People with Disabilities. Other declarations passed include; The International Year of the Disabled Persons of 1981 which emphasized the rights of people with disabilities and the Standard Rules on Equalizations of Opportunities of 1993. The rules enforced states to make a strong moral and political commitment to take action on equalization of opportunities for people with disabilities. The aim of the rule was to improve the quality of life of people with disabilities through full participation, which is inclusion (United Nations:2002).The Salamanca Statement of 1994 reiterated the right of education of every individual as stated in the 1948 Universal Declaration of Human Rights. It is also laid out basic policy changes needed to promote inclusive education, so that schools can serve all children, particularly those with disabilities. The Salamanca Framework for Action distinctively excludes the established of special schools which exclude children with disabilities from the society and promotes the philosophy of inclusion based on the human rights model. It strongly points out that ordinary schools should accommodate all children, regardless of their physical, intellectual, emotional, social, linguistic or other disabilities(Chireshe:2011).

Zimbabwe ,as a signatory to several Inclusive Education-related international charters and conventions was mandated to initiate and support inclusive programs for people with disabilities (PWD).Efforts have been made through drafting legislation, which was not comprehensive and specific to inclusion of PWD. The education Act of 1987 stated that, 'every child in Zimbabwe shall have the right to school education' and it is important to note that no mention whatsoever is made of the right of children with disabilities to inclusive education. On the other hand the Zimbabwean Disabled Persons Act of 1992 addresses the rights of people with disabilities in relation to education, employment, recreational facilities and community and social services but it is important to note that this Act fell under the Ministry of Education, Sport, Arts and Culture. It does not commit the Government providing Inclusive Education in any concrete way. Their efforts end at integration through resource units and special classes. This was also confirmed by the Nziramasanga Commission of 
Inquiry into Education and Training in Zimbabwe 1999 which observed that the Inclusive Education proclaimed by the government by then was mainly theoretical. The commission recommended that the real and serious Inclusive type of Education needed to be adopted at all levels of education system. This came against a background of practices of integration, mainstreaming or social and community rehabilitation (Hapanyengwi: 2009). Of late, there have been attempts towards Inclusive Education in a number of schools in Zimbabwe but it has been a trend that projects for PWD collapsed due to lack of support and resources. For example, some of the inclusion programs which were started in both rural and urban areas collapsed at the commencement of economic hardships and restrictions in Zimbabwe.Presently, the School Psychological Services (SPS) and Special Needs Education (SNE) are facing challenges in implementing their awareness and advocacy programmes on Inclusive Education in all the 73 districts across Zimbabwe because of lack of financial, human and material resources. Cash flow from the government continues to be a challenge and with no money it has been difficult for the SPS and SNE to implement Inclusive Education. This has also confined people with disabilities to institutions where they face stigmatization and continue to be excluded from the mainstream activities. In rural areas many PWD remain confined to the boundaries of their homes as many schools still have no resources of including them. As a result, equal participation has remained a dream for people with disabilities in Zimbabwe.

Leonard Cheshire Zimbabwe Trust seems to have brought hope for equal participation for people with disabilities by initiating Education. Leonard Cheshire Zimbabwe Trust (LCZT) signed a memorandum (MOU) with the Ministry of Education, Sports, Arts and Culture(MOESAC) in November 2009 as a way of partnering with Ministry on special pilot program, with a special focus on Inclusive Education at some 21 Schools in 5 districts (Leonard Cheshire Disability:2012).On the $21^{\text {st }}$ of January 2010,the Inclusive Education implementation was adopted and unanimously agreed upon at an stakeholder workshop that was convened under the auspices and guidance of the Director of Schools Psychological Services and Special Needs Education at the Education Services Centre, in Harare (Leonard Cheshire Disability:2011).The Inclusive Education Pilot programme will run for three years after which it may be reviewed. With the history showing two years of implementation at the moment, this researcherss has felt it is necessary to evaluate the progress made by LCZT since the initiative started.

Historically, Leonard Cheshire Zimbabwe Trust (LCZT) is a non-profit organization registered in Zimbabwe since 1981 as a clarity organization. It has since moved from charity to rights based approach which fosters inclusion of children with disabilities within communities (Leonard Cheshire Disabilities: 2012).It is a member of the Leonard Cheshire Disability Global Alliance. It endeavors to address the needs of children and youths with disabilities and campaigning for the promotion of change to help move policy and practice towards their real inclusion and participation. It also aims at facilitating and accessibility of children and youths with disabilities into mainstream schools, health care and economic empowerment. The LCZT 2011 annual report has also shown some successes in the provision of assistive devices to 42 students, complete infrastructure adaptations in 18 to 21 targeted schools, about 5500 people were reached through community awareness and about 436 children were assessed and enrolled in targeted schools (Leonard Cheshire Disability: 2011).As a result the researcherss undertook to evaluate the progress made by LCZT.

\subsection{Meaning of Inclusive Education}

\section{Literature Survey}

Inclusive education differs from previously held notions of 'intergration' and 'mainstreaming', which tended to be concerned principally with disability and 'special educational needs' and implied leaner's changing or becoming 'ready for' or deserving of accommodation by the mainstream. By contrast, inclusion is about the child's right to participate and the school's duty to accept the child. Inclusion rejects the use of special schools or classrooms to separate students with disabilities from students without disabilities. A premium is placed upon full participation by students with disabilities and upon respect for their social, civil and educational rights. Fully inclusive schools, which are rare, no longer, distinguish between 'general education" programs; instead, the school is restructured so that all students learn together (Schultz: 2007).

Rather than being a marginal issue on how some learners can be integrated in mainstream education, inclusive education is an approach that looks into how to transform education systems and other learning environments in order to respond to the diversity of learners. It aims towards enabling teachers and learners both to feel comfortable with diversity and to see it as a challenge and enrichment of the learning environment, rather than a problem. Inclusion emphasizes providing opportunities for equal participation of persons with disabilities (physical, social and or/emotional) whenever possible into general education, but leaves open the possibility of personal choice and options for special assistance and facilities for those who need them (UNESCO: 2009).Inclusive education involves changes and notifications in content, approaches, structures and strategies, with a common vision that covers all children of the appropriate age range and a conviction that it is the responsibility of the regular system to educate all children (UNESCO: 2003) IE is therefore an effort to make 
sure students with disabilities go to school along with their friends and neighbours while receiving whatever,' specially designed instruction and support" they need to achieve high standards and succeed as learners to become productive full members of the society. In a similar vein, Armstrong (2005) pointed out that Inclusive Education means transforming the entire educational systems to remove barriers to all learners thereby providing all children with equitable access to quality education.

\subsection{Strategies for Effective Inclusive Education of Children with Disabilities}

Radical changes are required in education systems, and in the values and principles of the people involved in delivering education, if the world's most vulnerable and disadvantaged children are to gain access to their local school. Research has shown that strategies for effective IE of children with disabilities were developed based on the International Declarations and Conventions, and the most effective ones being the Salamanca Statement of 1994 and the World Education Forum meeting held in Dakar in 2000 (Miles\&Singal:2008, Chireshe:2011,Mutepfa,Mpofu \& Chataika:2007,UNESCO: 2009).Different types of strategies for inclusive education are listed and explained hereunder:

\subsubsection{Policy Statement}

As already stated above, the United Nations' declaration of the Standard Rules on Equalization of Opportunities, 1993 and the Salamanca Statement 1994 was a great movement to enforce governments implement the agreements in their countries by introducing policies which support the declarations. The Equalization of Opportunities for Persons with Disabilities states that "states should recognize the principle of equal primary, secondary and tertiary educational opportunities for children, youths and adults with disabilities in integrated settings; thus inclusive education (Human rights: 2011).On the other hand, the Salamanca Statement of 1994 has sensitized governments about the concept of inclusion, and the implementation based on school, home community and employment (Sierra\& Towell:2011).

Firstly, inclusive values and beliefs are to be reflected I the policies framed (at the national, school and classroom level) and the education systems that is built (Miles\& Singal:2008, Chireshe:2011.Mutepfa,Mpofu \& Chataika (2007) in support pointed out that IE can only be achieved through laws and legislation pertaining to the issues of inclusion. Secondly, laws and legislation need to stipulate that everyone's need, including people with disabilities is to be catered for under the same law if the nations are to promote inclusion. States need to that disability aspects are included in all relevant policy making and national planning including budgeting of finances.

UNESCO (2009) emphasized that International Conventions should be signed and ratified and reflected in national legislation. The national legislation should be changed and revised to incorporate notions of Inclusive Education. Finally, implementation of policy and laws should be promoted and enforced according to the International Declarations and Conventions on disability rights. The government's priority in national policy, planning and implementation should be reflected in the comparative allocation in national budgets and in requests for development assistance from international partners and private sector (UNESCO: 2008).Appropriate monitoring and evaluation mechanisms need to be put in place to evaluate the of inclusive education policies as regards to the leaner, the education system and the whole society. Research has shown that developed countries like the USA, Canada and United Kingdom have put in place policies which have promoted inclusive education of people with disabilities. In the USA the individuals with Disabilities Education Act (IDEA) which specifically supports inclusive thinking and practice has been people with disabilities in the USA being educated in public schools like any other child without disabilities (Nevada Partnership in Inclusive Education:2011)

\subsubsection{Attitudinal Changes}

Change of attitudes towards people with disabilities play a big role in promoting inclusive education. Once laws are in place there is need for awareness programmes within the community to promote positive attitudes towards persons with disabilities. In his research on inclusive education in Zimbabwe, Chireshe (2011) found out that a culture of positive attitudes among families, teachers, and pupils and among the public at large towards persons with disabilities is very essential if inclusive education is to succeed. All researchersss agree that various awareness programs are ideal avenues to promote the development of positive attitude in inclusive education (UNESCO:2009,Donaldson: 2005,Mutepfa et al:2007).Donaldson (2005) pointed out that inclusion often requires shift in people's attitudes and values. Such change takes time and involves significant reassessment of conceptions and the role behavior. Awareness raising should involve both better understanding of inclusive education and that societies become more tolerant and understanding (UNESCO: 2009).Accepting change is really about learning. There is general agreement that teacher's attitudes, beliefs and skills are critical in successfully including marginalized and excluded children in education (Chireshe: 2011; Hastings and Oakford: 2003; Parasuram: 2006; Chataika et al: 2007; Peters (2004) further stated that schools should foster 
environments where teachers learn from experience in the same way that they expect their pupils should learn from the tasks and activities in which they engaged. Literature review shows that the teacher training and other service providers are important to the success of inclusive education. Teachers and other professionals who deal with children with disabilities should be taught about the different disabilities to understand these children and remove the myths about them (Chitiyo and Wheeler, 2004).Through training teachers and other professionals will also be equipped with teaching methods appropriate for children with disabilities. With such knowledge and skills teachers and other professionals will have a positive attitude towards children with disabilities because they will know what they are dealing with and how to handle students with disabilities.Chireshe (2011) observed that funding has an important role for the provision of resources for professional development, awareness and advocacy on inclusive education to change the negative attitude to positive attitude towards people with disabilities. Research has also highlighted provision of resources as key to inclusive education towards people with disabilities. Research has also highlighted provision of resources as key to inclusive education (Guralnick: 2001, Chireshe: 2011.)These resources range from funding human resources teaching, learning materials, technology, and infrastructure. Torreno (2011) postulated that inadequate funding can hinder on-going professional development that helps keep both specialists and classroom teachers updated on the best practices of inclusion.

\subsubsection{Accessible and Flexible Curricular}

According to UNESCO (2005), accessible and flexible curricula can serve as the "key" to creating " schools for all".It is important that the curriculum be flexible enough to provide possibilities for adjustment to individual needs and to stimulate teachers to seek solutions that can be matched with the needs and abilities of each and every pupil. Many curricula expect all pupils to learn the same things, at the same time and by the same means and methods. But the pupils are different and have different and have different abilities and needs. General educators must be willing to work with inclusion specialists to make adaptations, modifications and accommodations in both teaching methods and classroom and homework assignments. Teachers should be flexible in how students learn and demonstrate knowledge and understanding(Torreno:2011). Written work, for example should be limited if a student cannot write and can accomplish the same or similar learning objective through a different method.Therefore, the curriculum must take into consideration the various needs of pupils to ensure " access for all". The researcherss observed that the curriculum is flexible it will not be mandatory for students with disabilities to write national examinations for being promoted to the next level of education.UNESCO (2005) emphasized that together with flexible curricula, flexible teaching-learning methodology should be introduced. Making this a reality involves other changes in policy including shifting away from long, theoretical, pre-service-based teacher training to greater, continuous, in service capacity building. Schools often need to be assisted in modifying subject matters and working methods and this should be linked to appropriate skills training.The researcherss observed that teaching methods and learning material should be responsive to the diversity needs and abilities of all learners including students with disabilities.UNESCO (2009)concurs that teachers as well school leaders must be encouraged to discuss learning and teaching as well as methods and possibilities for development. They must be given a chance to reflect together on their practice, and to influence the methods and strategies used in their classes and schools. Teachers must also be familiarized with new curricula and trained in addressing student performances. A child-centered curriculum is characterized by a move away from rote learning and towards greater emphasis on hands-on, experience-based, active and cooperative learning.

\subsubsection{Conducive School and Classroom Environments}

Obviously, a student with a disability cannot learn in an inclusive classroom if he/she cannot enter the room, let alone the school building. Just as the curriculum should be accessible the environment should be accessible to people with disabilities.Torrento (2011) and Mett (2004) agreed that environment barrier is therefore one factor which excludes children with disability from regular schools. In Zimbabwe many schools are still inaccessible to students in wheel chairs or to those with other mobility aides and need elevators, ramps, paved pathways and lifts to get in and around buildings. Accessibility can go beyond passage ways, stairs, and ramps to recreational areas, paved pathways, and door handles (Torreno: 2011, Mett: 2004).For example a student with cerebral palsy, may not have the ability to grasp and turn a traditional doorknob.Classrooms must be able to accommodate a student's assistive technology devices, as well as other furniture to meet individual needs. According to Lang\& Charowa (2007) physical barriers refer to inaccessible roads, transport, and infrastructure, buildings, and schools clinics (with high concrete platforms, steps narrow entrances, slippery floors, etc.).The nature of impairment, the inhospitable physical infrastructure, particularly in rural areas seriously hampers people with disabilities from accessing mainstream services, hence preventing implementation of inclusive education.According to the United Nations (2006) Convention on the rights Of Persons with Disabilities, universal design means the design of products, environments, programmes, and 
services to be usable by all people, to the greatest extent possible, without the need for adaptation or specialized design.' Universal design" shall not exclude assistive devices for particular groups of persons with disabilities where this is needed. The first thing that greets a visitor to most public buildings is an array of stairs. These must be climbed before one can enter the building. Stairs are often the first barrier for many children and adults to access schools or other public buildings and enjoy the services these facilities have to offer. Some stairs have hand railings on the side to give support, but most do not. All public buildings should therefore offer alternative ways to enter. Ramps are in most cases easy and relatively inexpensive to build.UNESCO (2009) emphasized that when new school buildings are being planned, and designs are being developed, there is need to make sure that they are equally accessible for all. Ramps and walk always should be incorporated into design, in such a way that they do not become separate feature for children/teachers/parents with disabilities, women who are pregnant, and the elderly, but will be present attractive, alternative access-ways for all users. Kaplan (2007) agree that universal design is therefore not "just' access, but also about creating a more inclusive and learningfriendly environment in school. Schools that are built based on universal design principles will therefore be more effective because these schools will enable children to learn, develop, and participate, instead of " disable' children by creating barriers to their development and participation.The design for latrines in schools participating in the Water, Sanitation and Health Education (WASH) programme in Tajikistan is currently being redesigned to ensure improved accessibility for children with disabilities. The new design will make the latrines more user-friendly for all children in the school as they are more spacious, there will continue to be separate (and entrances for girls and boys and the new design will continue to be based on the same low cost philosophy as previous designs (UNICEF:2008).

Inaccessibility to toilet facilities was cited as one of the reasons for the high dropout rate among children with physical disabilities in the new report,' Disability is not inability' released by the Foundation for Human Rights Initiative (FHRI) in 2009. The report reveals that most schools use pit latrines, which are usually dirty. "Going to the toilet becomes an ordeal that the child dreads, and the humiliation makes many children stay home after a brief period of going to school. Many \{pit-latrines\} have narrow doors and steps and therefore impossible for a physically disabled child to crawl on the floor,' the report sadly reads, sadly, this is a challenge for many countries in Africa including Zimbabwe (Chitiyo and Wheeler: 2004, Musasizi: 2009).To make schools more accessible and friendly, colour coding could be used to identify different classrooms to ease orientation for children with low vision, as well as for children with developmental impairment. It will also make the school more cheerful for all. Braille or other tactile symbols should mark every door to ease orientation for children with visual impairment. Sound/noise levels should be reduced by using curtains, textile wall decorations, and other sound-dampening materials. Specially- designed furniture should be made available for those who need chairs and tables that differ from standard classroom furniture. This does not have to be expensive. Chairs that enable children who have different body sizes to read and write comfortably could be designed based on local models. For example there can be a regular chair, adjusted chair with removable footrest or adjusted chair with foot -rest and higher seat to accommodate different physical disabilities (UNESCO:2009).Doors should be wide enough for wheel chairs to easily pass through and easy to open with lower handles.

In addition to the above strategies, UNESCO (2009) points out that monitoring and evaluation are necessary to improve planning and implementation of inclusive education. This can be achieved by developing systems for monitoring and evaluation that relate to all levels (national, regional, local and private) and improving monitoring and evaluation of performance at schools and in non-formal education programmes.The school heads, teachers and inspectors should be trained in assessment and evaluation of inclusive education programmes. Once school heads and education officers are equipped with such knowledge and skills it will be easier to implement inclusive education. According to Kaplan (2007) a new school building with access ramps, colour coding on walls and doors, colour marking and tactile patterns on the floors was constructed in Lombok (Indonesia).The building was planned and designed by teachers in the school and the headmaster monitored the construction process to ensure that the work was done according to specifications and remained within the budget, which was developed according to Indonesian government standards for school buildings. With such support from the teachers and administration, students with disabilities will fit in regular schools without any label. This also indicates positive attitude towards inclusive education for children with disabilities.For inclusive education to work, Musasizi (2009) noted that "there must be a restructuring of cultures, policies and practices in schools to respond to the diversity of pupils within the locality, identification and then reduction of the barriers to learning and participation, providing accessible curriculum and appropriate training programs for teachers".

\section{Problem Definition}

Efforts to mainstream children with disabilities in Zimbabwe have been met with various challenges. Inclusive Education programs have never reached fruition but they mainly ended at integration level. The focus 
of this study was to assess and evaluate the inclusive education pilot programme being implemented by Leonard Cheshire Zimbabwe Trust in conjunction with the Ministry of Primary and Secondary Education.

\section{Methodology}

The study employed the descriptive survey design due to the nature of the research. In this study, the target population was made up of all LCZT pilot primary schools in Harare region excluding Chitungwiza. Included were learners, teachers, school heads and parents. From these purposive sampling was used to come up with a representative sample of five teachers and five parents from each of the three schools in Harare. All three heads of the schools were added to the sample. The grand sample had a total of 15 learners, 15 parents, 15 teachers and 3 school heads. Questionnaires and semi structured interviews were the primary methods used to collect data. Observation was used as a secondary data collection technique. Thematic data analysis with some descriptive statistics was used to present and analyse data. However, it has to be noted that in this paper (part A), only the views of the teachers and school heads are presented and analyed. The views of the parents and those of learners with disabilities are presented in another paper, part B.

\subsection{Data Presentation from Questionnaires for Teachers.}

\section{Results}

Eighteen questionnaires were used in collecting data from teachers; 15 were teachers and 3 were heads of the three schools. The researcherss handed out the questionnaires to teachers. All questionnaires were returned and there was $100 \%$ return

\subsection{Table 2 Gender}

$N=18$

\begin{tabular}{|l|l|l|l|}
\hline & Frequency & Percent & Cumulative Percent \\
\hline Male & 2 & 11.1 & 11.1 \\
\hline Female & 16 & 88.9 & 100.0 \\
\hline Total & $\mathbf{1 8}$ & $\mathbf{1 0 0}$ & \\
\hline
\end{tabular}

Most of the respondents were female teachers. There were only a few teachers.

\subsubsection{Figure 1 Professional Qualification}

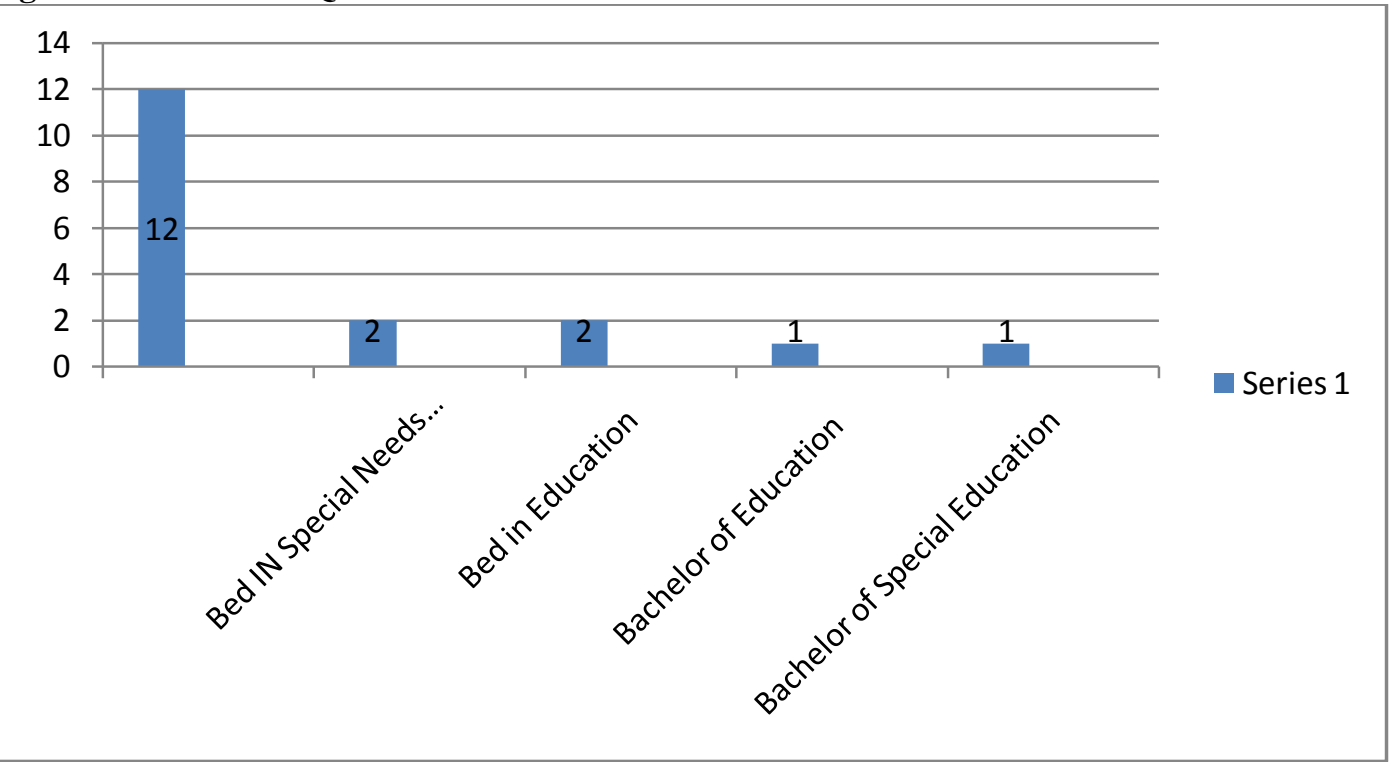

Most of the respondents had certificate/diploma in education as their highest professional qualifications.A few had degrees in Bed in Special Needs and Bed in Education as well as Bachelors in both Special Education and Education.

4.2.3 Table 3 Experiences in Teaching Children with Disabilities

\begin{tabular}{|l|l|l|l|}
\hline Duration & Frequency & Percent & Cumulative \\
\hline 0-5 years & 14 & 77.8 & 77.8 \\
\hline 6-10 years & 2 & 11.1 & 88.9 \\
\hline $11-15$ years & 2 & 11.1 & 100.0 \\
\hline Total & $\mathbf{1 8}$ & $\mathbf{1 0 0 . 0}$ & \\
\hline
\end{tabular}


The table shows that the majority of teachers had experience of between 0 to 5 years teaching children with disabilities. Only a few had an average experience of between 6 years and 15 years.

4.2.4 Figure 2 Experiences as a Head of an Inclusive School.

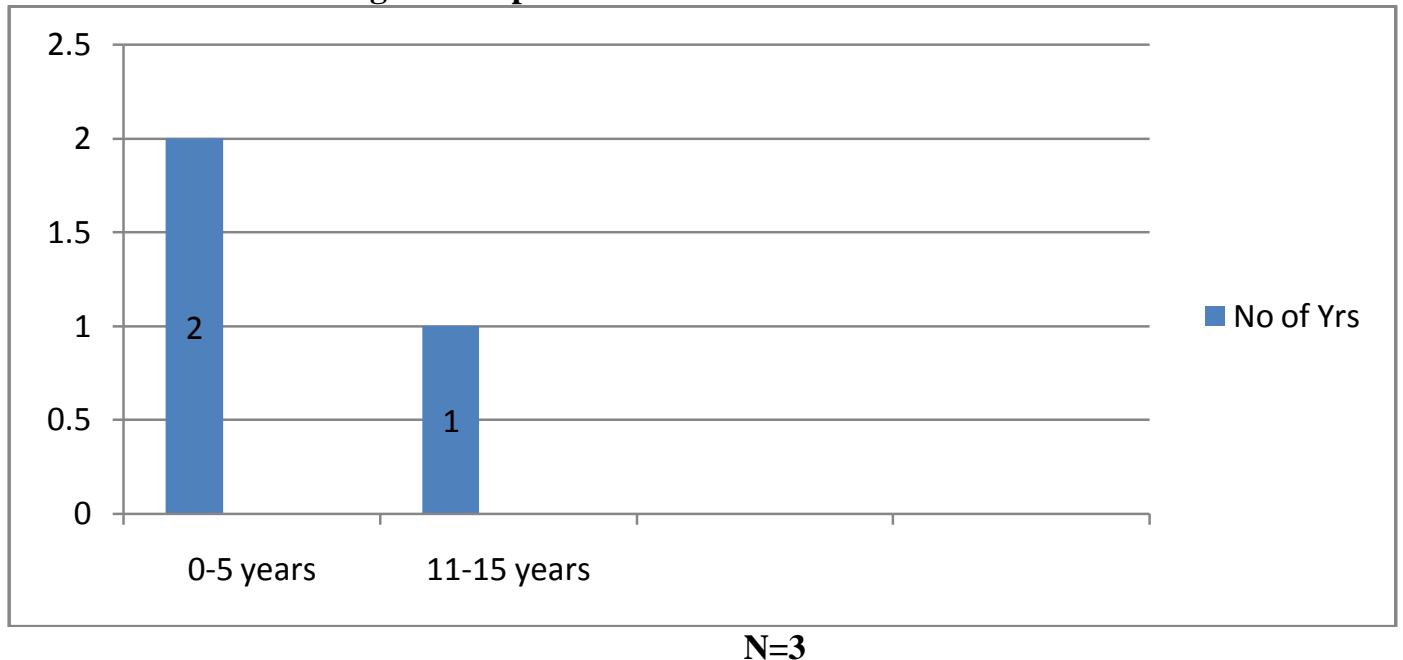

The table and graph show that the majority of the heads had fewer experiences in heading an Inclusive School.The majority started when inclusive education was started in those schools as pilot programme.

\subsubsection{Table 4 Overall Teaching Experience in Mainstream Schools.}

\begin{tabular}{|l|l|l|l|}
\hline & Frequency & Percent & Cumulative Percent \\
\hline $0-5$ years & 4 & 22.2 & 22.2 \\
\hline 6-10 years & 4 & 22.2 & 44.4 \\
\hline 11- 15 years & 5 & 27.8 & 72.2 \\
\hline 16- 20 years & 1 & 5.6 & 77.2 \\
\hline 20+ years & 4 & 22.2 & 77.8 \\
\hline Total & $\mathbf{1 8}$ & $\mathbf{1 0 0 . 0}$ & $\mathbf{1 0 0 . 0}$ \\
\hline
\end{tabular}

$\mathbf{N}=\mathbf{1 8}$

As shown from the table, only a few respondent had less years of teaching experience and the majority had 11 years and above of teaching experience. With such level of teaching experiences, the teachers were going to display a high level of maturity in responding in responding to questionnaires and were also going to give accurate and correct answers since they have been in the teaching service for a long time.

\subsubsection{Figure 3 Numbers of Students With and Without Disabilities in a Class.}

$\mathrm{N}=\mathbf{1 5}$

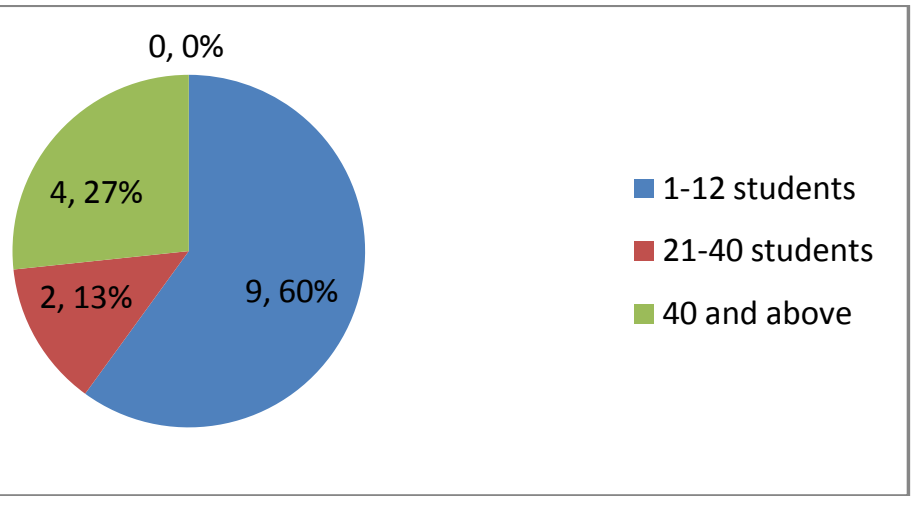

The pie chart shows that many teachers had very big classes and just a few teachers had an average of 20 students.Teacher - pupil ration was very high.

4.2.7 Table 5 Numbers of Students with Disabilities in a Class.

\begin{tabular}{|l|l|l|}
\hline & Frequency & Percent \\
\hline $1-3$ students & 14 & $93 \%$ \\
\hline $4-6$ students & 0 & $0 \%$ \\
\hline $7-9$ students & 1 & $7 \%$ \\
\hline $10+$ students & 0 & $0 \%$ \\
\hline & 15 & $100 \%$ \\
\hline
\end{tabular}


$\mathrm{N}=15$

The graph and the pie chart show that they were few students with disabilities in most of the regular classes in exceptional of 1 class which had 7-9 students. This was a Resource room class or Special class.

4.2.8 Figure 4 Use of Orthodidactic Methods such as Cooperative Learning,Multisensory and Peer Tutoring are necessary in an Inclusive Setting to meet individual Needs of both Children With and Without Disabilities.

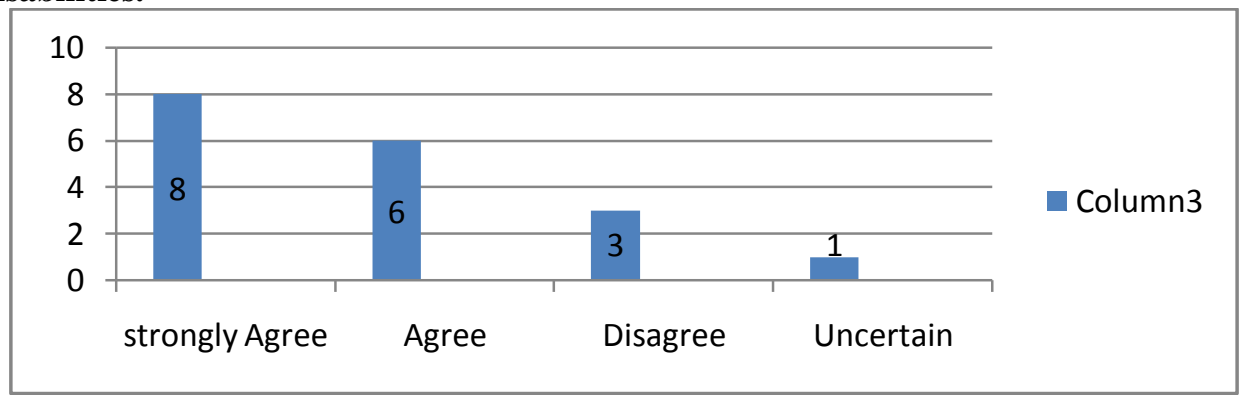

$\mathbf{N}=18$

Many teachers strongly agreed that the use of orthodidactic methods were necessary in an inclusive setting to meet the individual needs of both students with or without disabilities.However,a few disagreed and one was uncertain.

4.2.9 Figure 5 Schools always Provides Learning Materials that Promote the use of Appropriate Strategies when Teaching Children with disabilities.

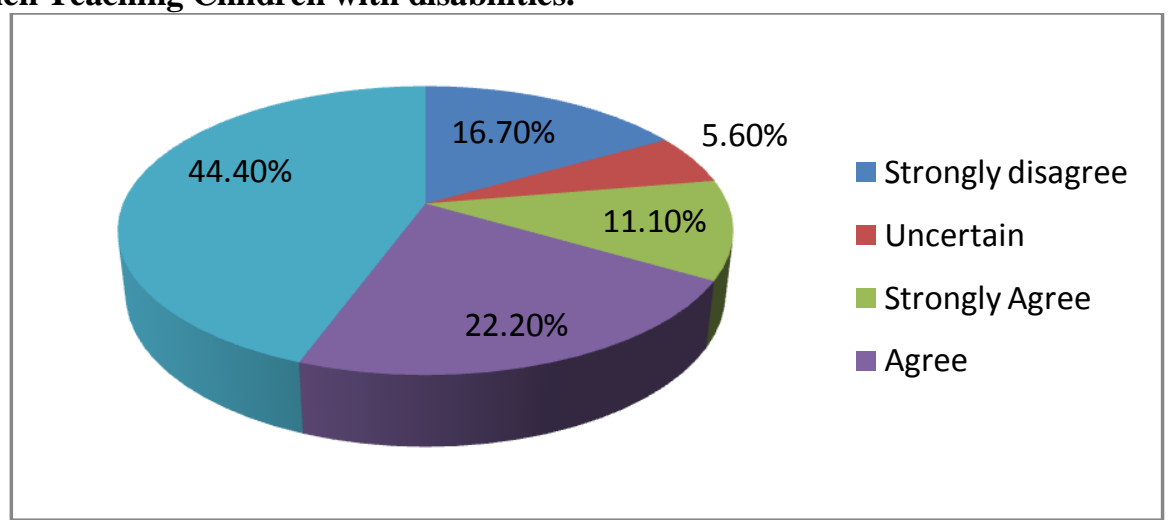

Most respondents disagreed that schools always provided learning materials that promoted the use of appropriate strategies when teaching children with disabilities. However, a few agreed and one was uncertain.

4.2.10 Table 6 Children with Disabilities always get the Needed Assistive devices e.g. Hearing Aids, Callipers etc.

\begin{tabular}{|l|l|l|l|}
\hline & Frequency & Percent & Cumulative Percent \\
\hline Agree & 1 & 5.6 & 5.6 \\
\hline Disagree & 9 & 50.0 & 55.6 \\
\hline Strongly Disagree & 7 & 38.9 & 94.4 \\
\hline Uncertain & 1 & 5.6 & 100.0 \\
\hline Total & $\mathbf{1 8}$ & $\mathbf{1 0 0 . 0}$ & \\
\hline
\end{tabular}

$\mathbf{N}=\mathbf{1 8}$

The table shows that the highest percentage was of respondents who disagreed and followed by those who strongly disagreed with only one who agreed that children with disabilities always got assistive devices and other one was uncertain. Overall, the majority disagreed. 
4.2 11 Figure 6 Teachers always hold Staff Development Workshops focusing on Teaching Strategies of Children with disabilities in an Inclusive Setting.

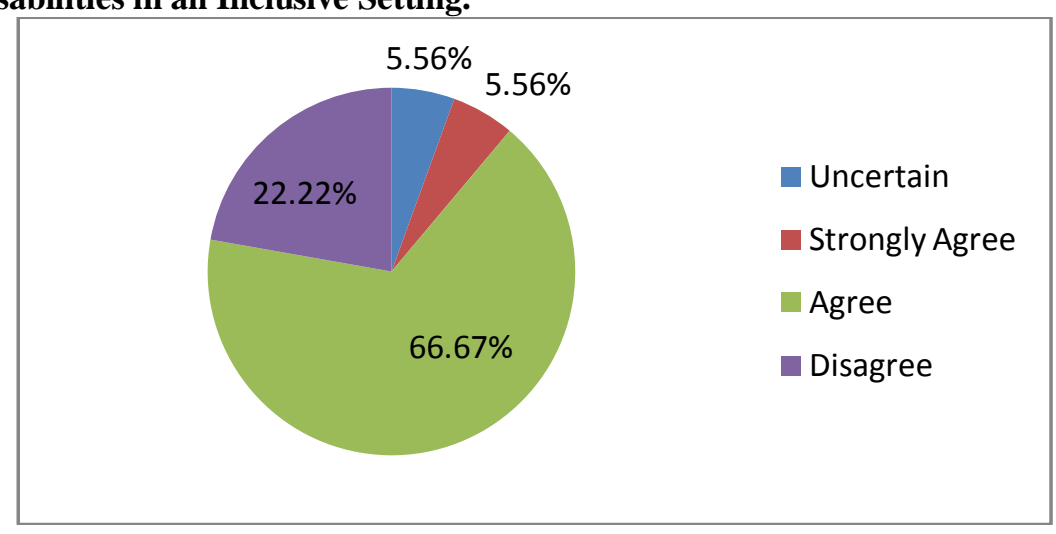

The pie chart shows that the majority of teachers agreed that staff development workshops are always held focusing on teaching strategies of children with disabilities. Only strongly disagreed and one was uncertain.

\subsubsection{Figure 7 There is Time for Teacher Collaboration and planning with other Specialists}

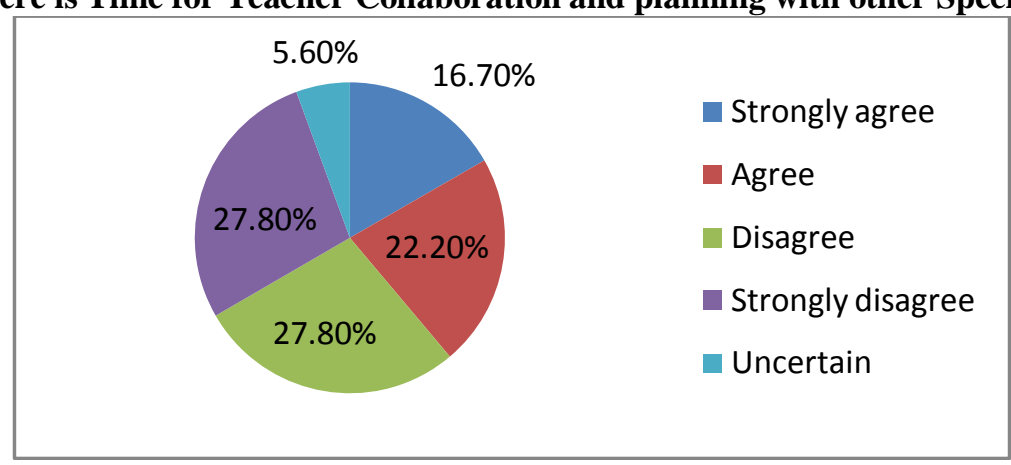

\section{$\mathbf{N}=\mathbf{1 8}$}

As shown by the pie chart there was a balance of respondents who strongly disagreed and disagreed that there was time for teacher collaboration with other specialists. However, a few agreed and one was uncertain.

4.2.13 Table 7 Leonard Cheshire Zimbabwe Trust (LCZT) Always Provides Adequate Materials/Resources to Meet Individual Needs of Children with Disabilities

\begin{tabular}{|l|l|l|l|}
\hline & Frequency & Percent & Cumulative Percent \\
\hline Strongly Agree & 1 & 5.6 & 5.6 \\
\hline Agree & 7 & 38.9 & 44.4 \\
\hline Disagree & 7 & 38.9 & 83.3 \\
\hline Uncertain & 3 & 16.7 & 100.0 \\
\hline Total & $\mathbf{1 8}$ & $\mathbf{1 0 0 . 0}$ & \\
\hline
\end{tabular}

The results of the study indicated that there were an equal number of respondents of those who disagreed and those who agreed that LCZT always provided adequate materials/resources to meet the individual needs of children with disabilities. This showed that some of the schools received resources while others did not receive any resources from LCZT.However, a few were uncertain and some disagreed.

\subsubsection{Figure 8 LCZT always Funds Workshops on Disability Issues in an Inclusive Setting.}

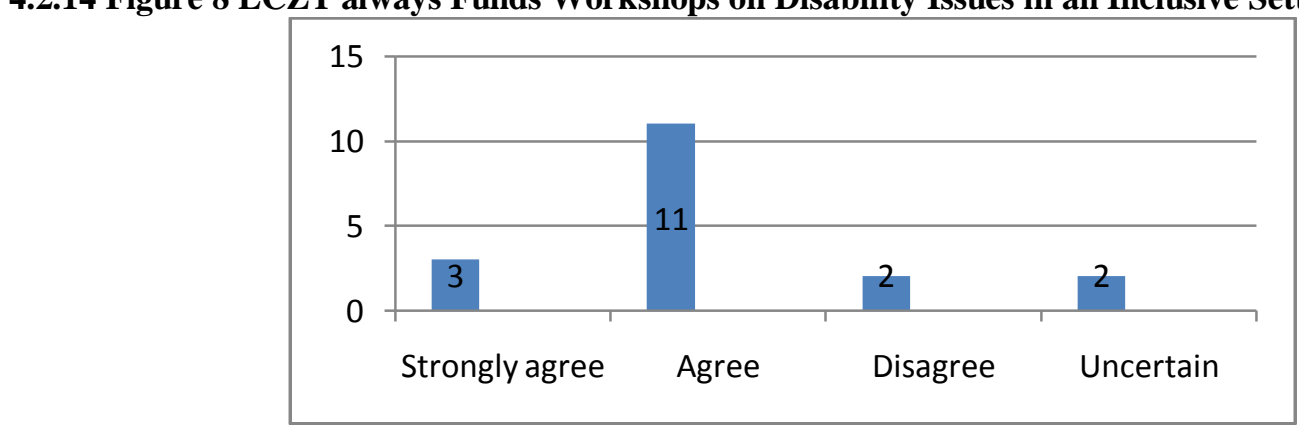

$\mathrm{N}=18$ 
Both the table and the graph show that LCZT always funded workshops on disabilities issues in an inclusive setting. This was shown by the majority of respondents who agreed that they were funding workshops. However, few disagreed and two were uncertain.

4.2.15 Table 8 LCZT Always Adopts the whole School Support Model When Funding School Programmes.

\begin{tabular}{|l|l|l|l|}
\hline & Frequency & Percent & Cumulative Percent \\
\hline Strongly Agree & 1 & 5.6 & 5.6 \\
\hline Agree & 5 & 27.8 & 33.3 \\
\hline Disagree & 6 & 33.3 & 66.7 \\
\hline Uncertain & 6 & 33.3 & 100.0 \\
\hline Total & 18 & 100.0 & \\
\hline
\end{tabular}

$\mathbf{N}=\mathbf{1 8}$

The results show that the percentage of teachers who disagreed is the same as those who were not certain about LCZT adopting the whole school support model when funding school programmes.H; owever, results showed that other teachers almost of the same percentage agreed that LCZT adopted the whole school support model when funding. This shows that schools received support services at different frequiencies.

4.2.16 Figure 9 LCZT involvement in Planning Educational Programmes in an Inclusive School Setting is Significantly High.

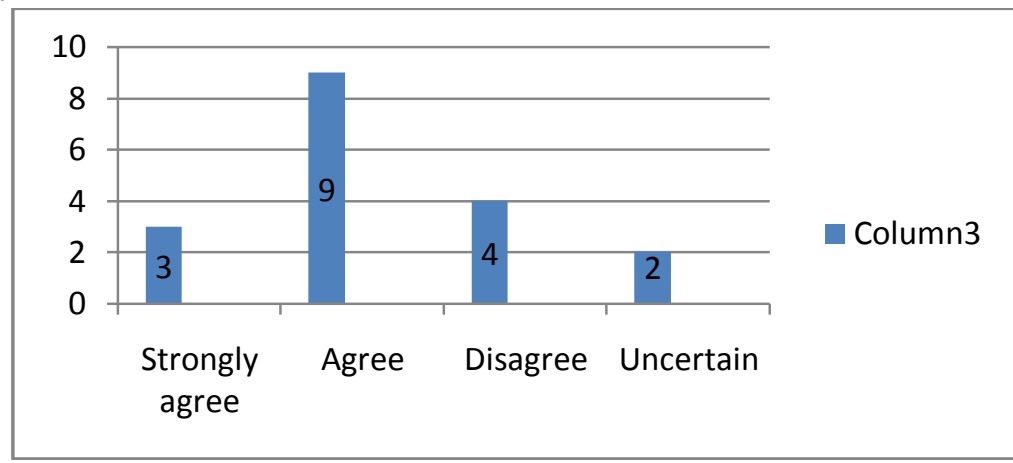

$\mathbf{N}=\mathbf{1 8}$

The results on the bar graph show that the majority of the respondents agreed that LCZT involvement in planning educational programmes in an inclusive school setting was significantly high. Only a few disagreed and two were uncertain.

4.2.17 Figure 10 LCZT frequently Visits the School for Monitoring Progress of Inclusion.

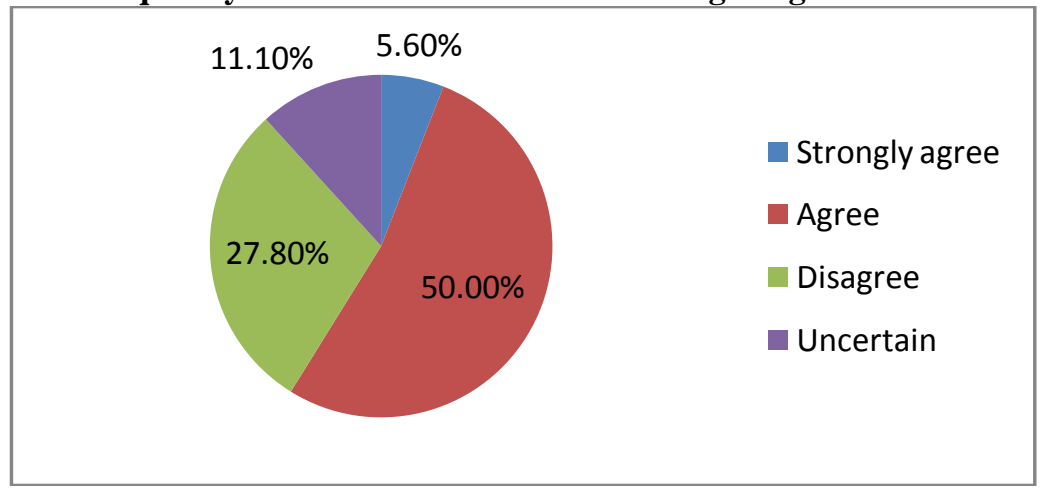

$\mathbf{N}=18$

The pie chart shows that the majority of the respondents agreed that LCZT frequently visited the school for monitoring of inclusion. A few respondents disagreed.

4.2.18 Table 9 Students with Disabilities Perform just like other without Disabilities in an Inclusive Setting.

\begin{tabular}{|l|l|l|l|}
\hline & Frequency & Percent & Cumulative Percent \\
\hline Strongly Agree & 3 & 16.7 & 16.7 \\
\hline Agree & 6 & 33.3 & 50.0 \\
\hline Disagree & 7 & 38.9 & 88.9 \\
\hline Strongly Disagree & 1 & 5.6 & 94.4 \\
\hline Uncertain & 1 & 5.6 & 100.0 \\
\hline Total & $\mathbf{1 8}$ & $\mathbf{1 0 0 . 0}$ & \\
\hline
\end{tabular}


$\mathbf{N}=\mathbf{1 8}$

The graph shows that the majority of respondents agreed that students with disabilities performed just like other students in an inclusive setting. A significant number has also disagreed

4.2.19 Figure 11 Students with Disabilities have good Friendship with other Students without Disabilities.

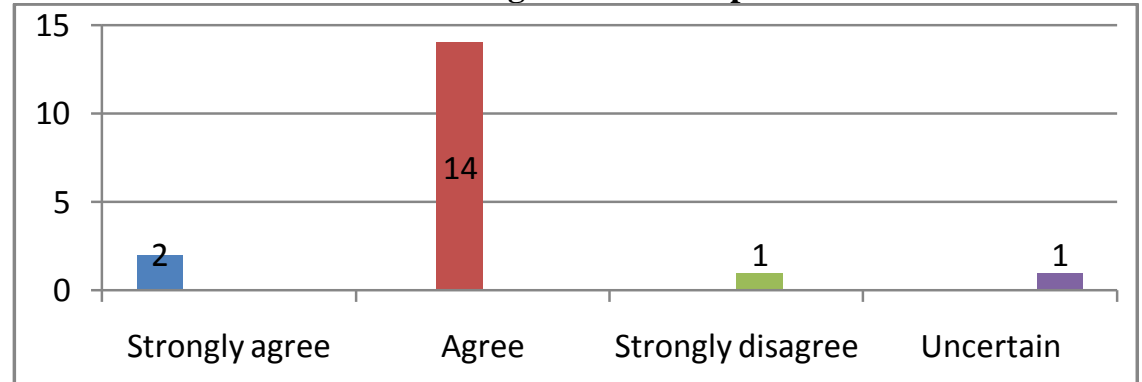

\section{$\mathbf{N}=18$}

The bar graph shows that most of the respondents agreed that students with disabilities had good friendship with other students without disabilities.

\subsubsection{Figure 12 All efforts by LCZT result in Full Implementation Of Inclusion of Children with} Disabilities.

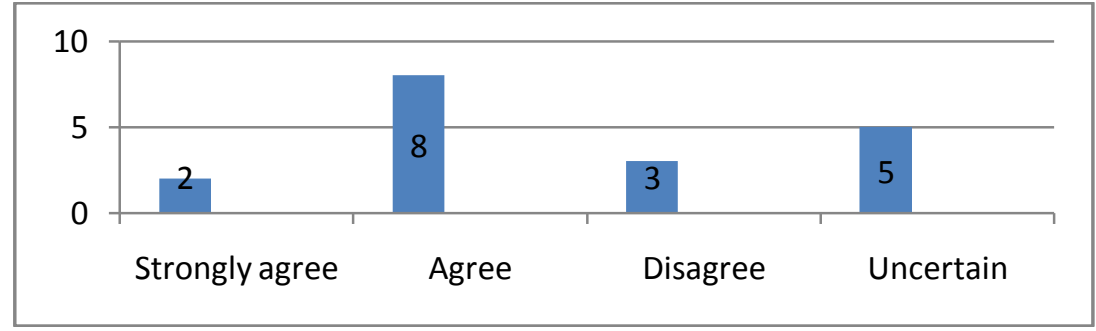

$\mathbf{N}=18$

The majority of the respondents agreed that all the effort by LCZT resulted in the full implementation of inclusion of children with disabilities. However, a few were uncertain and others disagreed.

4.2.21 Table 10 All students with Disabilities are Assessed and an Individualized Educational Plan is prepared by a team of professionals.

\begin{tabular}{|l|l|l|l|}
\hline & Frequency & Percent & Cumulative Percent \\
\hline Strongly agree & 2 & 11.1 & 11.1 \\
\hline Agree & 4 & 22.2 & 33.3 \\
\hline Disagree & 1 & 5.6 & 38.9 \\
\hline Strongly Disagree & 5 & 27.8 & 66.7 \\
\hline Uncertain & 6 & 33.3 & 100.0 \\
\hline Total & $\mathbf{1 8}$ & $\mathbf{1 0 0 . 0}$ & \\
\hline
\end{tabular}

$\mathrm{N}=18$

The table shows that the majority of the respondents were uncertain that all students with disabilities were assessed and an individualized Educational Plan was prepared by a team of professionals. However, there was a slight difference registered between those who were uncertain and those who strongly disagreed. The table also reveals that there was a balance between the three categories of those who agreed, disagreed and the uncertain. This showed that assessment was practiced in one of the schools and not done in the other two.

\subsubsection{Figure 13 The curriculum is flexible to allow Variation in Working Methods.}

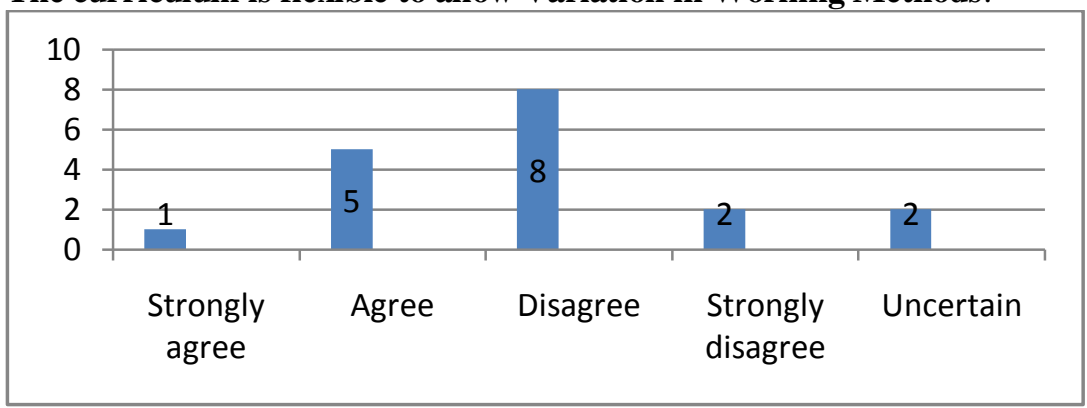

$\mathbf{N}=18$ 
The majority of respondents disagreed that the curriculum was flexible to allow variation in working methods. However a few agreed and the two were uncertain

4.2.23 Table 11 The Parents Take an Active Role in the Education of their Children.

$\mathbf{N}=18$

\begin{tabular}{|l|l|l|l|}
\hline & Frequency & Percent & Cumulative Percent \\
\hline Strongly Agree & 2 & 11.1 & 11.1 \\
\hline Agree & 12 & 66.7 & 77.8 \\
\hline Disagree & 1 & 5.6 & 83.3 \\
\hline Strongly Disagree & 3 & 16.7 & 100.0 \\
\hline Total & $\mathbf{1 8}$ & $\mathbf{1 0 0 . 0}$ & \\
\hline
\end{tabular}

The table shows that most respondents agreed that parents took an active role in the education of their children. However, a few disagreed.

4.2.24 Table 12 The concept of inclusive education is well known and accepted by teachers, parents and students.

\section{$\mathbf{N}=18$}

\begin{tabular}{|l|l|l|l|}
\hline & Frequency & Percent & Cumulative Percent \\
\hline Strongly Agree & 2 & 11.1 & 11.1 \\
\hline Agree & 6 & 33.3 & 44.4 \\
\hline Disagree & 6 & 33.3 & 77.8 \\
\hline Strongly Disagree & 1 & 5.6 & 83.3 \\
\hline Uncertain & 3 & 16.7 & 100.0 \\
\hline Total & 18 & 100.0 & \\
\hline
\end{tabular}

The table recorded the same number of frequencies of respondents who agreed to those who disagreed that the concept of inclusive education is well known and accepted by teachers, parents and students. Only a few were uncertain

\subsubsection{Figure 14 Awareness Programmes have been launched to Support Inclusive Education.}

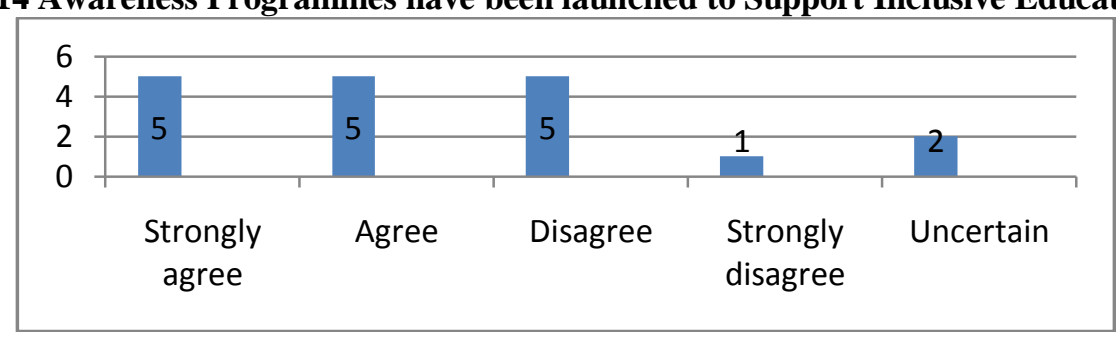

$\mathbf{N}=18$

The bar graph shows that there was a balanced distribution of respondents between those who strongly agreed, agreed and disagreed that awareness programmes had been launched to support inclusive education. However, one strongly disagreed and two were uncertain.

\subsubsection{Figure 15 Possible Solutions towards the implementation of Inclusion for Students with Disabilities} in Mainstream/Regular Schools.

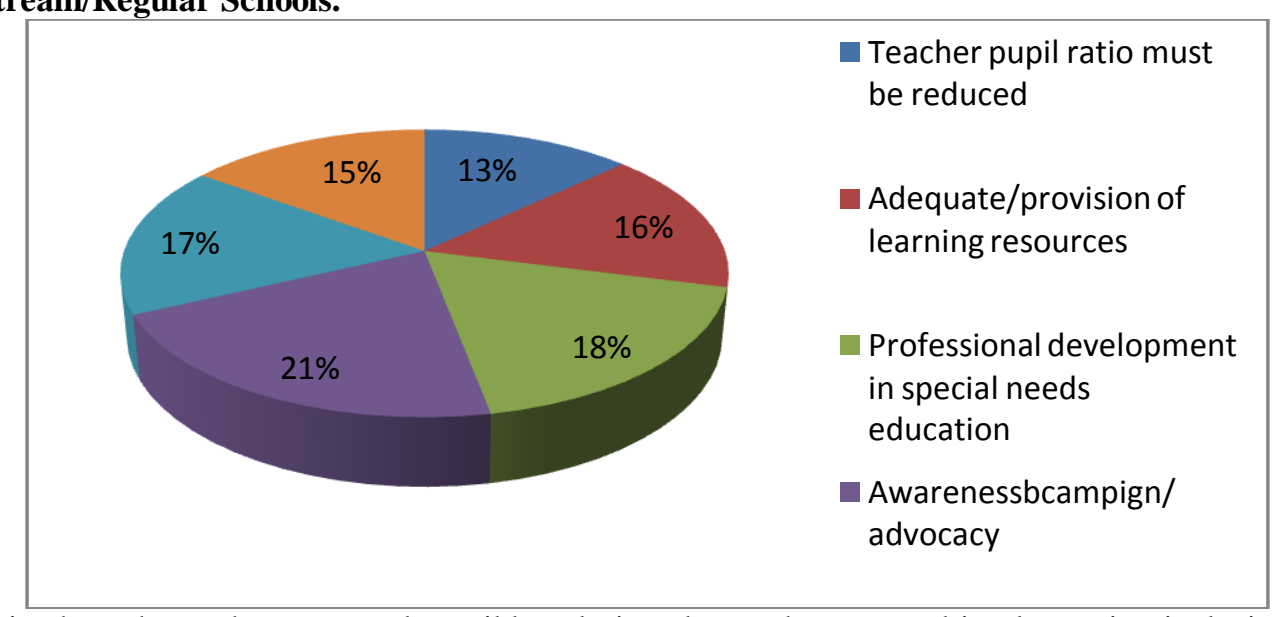

The pie chart shows the suggested possible solutions by teachers toward implementing inclusion the study showed that Awareness Campaigns and Professional Development were preferred by the majority of the respondents. 


\section{Discussion}

According to UNESCO (2009), inclusion philosophy is based on the Humanist Theory, the rights model. A rights based approach to education is founded upon three principles which are access to free and compulsory education, equality, inclusion and non-discrimination. Therefore a move towards inclusion is not simply a technical or organizational change but also a movement with a clear philosophy. Research has shown that strategies for effective education of children with disabilities were developed based on the International Declarations and Convention, and the most effective ones being the Salamanca Statement 1994 and the World Forum meeting held in Dakar in 2000 (Miles and Singal : 2008, Chireshe: 2011,UNESCO : 2009). The study revealed that Leonard Cheshire Zimbabwe Trust used some of the strategies to implement inclusive education in the Zimbabwean Primary Schools.

The study revealed that LCZT's main goal was to provide education to children with various disabilities in their regular local schools. The statistics on the demographic characteristics of children with disabilities showed that many children with different disabilities had joined the pilot schools to learn with other children without disabilities in their neighbourhood when they were launched in 2010.The Salamanca Statement and Framework for Action (1994) asserted that:"Regular schools with inclusive orientation are the most effective means of combating discrimination, creating welcoming communities ,building an inclusive society and achieving education for all."One parent expressed with happiness, it is good that my son is going to school with others, before inclusive education, I could not afford a special school for with hearing impairment, so my child was just staying home". The different types of disabilities and age groups found in inclusive schools also showed that LCZT is making great effort to realize the goals of inclusion. Support given to some of the students who needed wheel chairs and ramps to access school showed how determined LCZT was in achieving the goal of inclusive education.

Study results also showed that teachers were aware that using orthodidactic methods such as cooperative learning, multisensory and peer tutoring were necessary in an inclusive setting to meet the individual needs of both students with or without disabilities.However, through observation the researchers observed that teachers continued to use traditional methods of teaching. Reasons for this were drawn from the study results which showed that there were no adequate resources to use when teaching children with various disabilities. Another important factor was that teachers had no time for collaboration with specialists to learn more about teaching children with disabilities. Chitiyo and Wheeler (2004) concurred with this idea when they with this idea when they explained that through training, teachers and other professionals will also be equipped with teaching methods appropriate for children with disabilities. The findings have revealed that many teachers in the three inclusive schools had no Special Needs Education qualifications. They were just ordinary mainstream teachers. Statistics showed that $17 \%$ were qualified Special teachers compared to $83 \%$ who were mainstream trained teachers. The findings showed that LCZT was aware of this shortfall and understood the importance of providing teachers with skills in order for it to achieve inclusive education. This was revealed in the teacher questionnaire, when the majority of teachers agreed that staff development workshops were always held focusing on teaching strategies of children with disabilities.

Chireshe (2011) observed that funding has an important role for the provision of resources for professional development for the provision of resources for professional development; awareness and advocacy on inclusive education to change the negative attitude of teachers and the community to positive attitude towards people with disabilities. The majority of teachers agreed that funding was provided by LCZT for workshops on disability issues in an inclusive setting. Research has also shown mixed results from teachers in awareness programmes.There was a balanced distribution of respondents between those strongly agreed, agreed and disagree. This revealed uneven distribution of service by LCZT to its pilot schools. The findings further revealed that $80 \%$ of parent respondents said that there were no awareness programmes on children with disabilities and inclusion in their communities. One parent commented that,' only once at a church gathering. LCZT came and spoke about children with disabilities". The researchers found that in two years, LCZT was seen and heard once in a community. This was supported by Chireshe (2011) in his research on inclusive education in Zimbabwe when he concluded that a culture of positive attitude among families, teachers ,pupils and the public at large towards persons with disabilities was very essential if inclusive education was to succeed and this could only be achieved through awareness campaigns and advocacy.

Torento (2011) and Mett (2004) agreed that environment barrier was therefore one factor which excluded children with disabilities from regular schools. In Zimbabwe, many schools are still inaccessible to students in wheelchairs and those with mobility aides and needed ramps, paved pathways and lifts to get in around buildings. Unfortunately, the results of the study have shown that the physical environment of the schools were not yet conducive to people with disabilities. Through observation, the researcherss found out that there were few ramps and pathways in two of the three schools; classrooms and some toilets were not accessible to those using wheel chairs. As a result these two pilot schools had limitations in enrolling children with physical disabilities. In one of the schools, the visitor was greeted by an array of stairs, which remained the first 
barrier of children with physical disability. However; one of the schools had put in place ramps, widened doors for both the classrooms and toilets. Children with disabilities were enrolled because barriers were removed.

\section{Recommendations}

$>$ There is need for awareness programmes within the community to promote positive attitudes towards people with disabilities. Raising awareness should involve both better understanding of inclusive education and people with disabilities.

$>$ Accepting change is really about learning. Training of regular teachers and other professionals who deal with children with disabilities is to equip them with the teaching methods appropriate for children with disabilities and type of interventions to use. Such knowledge creates positive attitudes towards children with disabilities.Therefore; there is need for vigorous training of all regular teachers and other professionals for them to understand children with disabilities.

$>$ Creating accessible and flexible curriculum should serve as key to creating inclusive education. It is important that the curriculum be flexible enough to provide possibilities for adjustment to individual needs and to stimulate teachers to seek solutions that should be matched with the needs and abilities of each and every student. For example, a Zimbabwe curriculum is not flexible as it is examination centered.

$>$ It is vital for all stakeholders to work together to create conducive schools and classroom environments for children with disabilities. All old school buildings in Zimbabwe need ramps, paved pathways, wider doors and suitable handles to get in and around buildings. Toilets and classrooms should be accessible to all children.

> Zimbabwe needs formalized process of identifying and evaluating children with disabilities. As it stands, classification is not mandatory which make it difficult for teachers to design an appropriate education plan for a child. Assessment centers close to schools are ideal for early clinical identification, diagnosis, appropriate intervention and placement for children with disabilities.

$>$ There is need to create partnership and collaboration with other non-governmental organizations, the community and the government to contribute to the funding of inclusive programmes.

$>$ Government of Zimbabwe through its Ministries and Heads of Schools should be able to effectively plan and budget for buying resources to support inclusive education. Schools should not just wait for LCZT to provide them with all resources but take initiatives to put in place, for example ramps and pathways.

$>$ Both the government and LCZT should put in place monitoring and evaluation systems which are necessary to improve planning and implementation

$>$ For Zimbabwe's inclusive education to be successfully implemented, a policy framework and legislative support should be put in place at the national level. Once law is in place all stakeholders would be able to launch funding and awareness to promote inclusive education.

\section{References}

[1]. Amnesty International (2011).Human Rights.Online.Available url: http:www,amnestyyusa.org/human- rughts/page.do?id=1031002 Accessed 23 April 2012

[2]. Armstrong ,D(2005) Voice,Rituals and Transitions: What is inclusive Education Really About? Paper Presented at the Inclusive and Supportive Education Congress, in Univerdty of Strathclyde,Glasgow,Scotland,August 1 to 4,2005 .

[3]. Byangisha,A (2007) Inclusive Education Uganda:The Way for the Future.Online.Available url: http:// www.ibe.unesco.org/fileadmin/user/upload/Inclisive-Education/Reports/mairobi-07/uganda-inclusion-07.pdf Accessed 25/06/12

[4]. Chireshe,R(2011).Special Needs Education In Service Teacher Trainees' Views on Inclusive Education In Zimbabwe.Online.Available url: http:// www.krepublishers.com/02-Journals/JSS/JSS-27-0-000-11-Web/JSS-27-3-00011=Abst=PDF/JSS-27-3-157-11=1194- Chireshe-R-Tt.pdf.Accessed on 22/04/2012

[5]. Chimonyo,I Kaputa,T.M.,Mamvura,EK.,Hlathwayo,L,Munemo,E.T., Nyatsanza,T.D and Mutandwa.E(2011)Breaking Down Barriers to Inclusive Education In Zimbabwe.A Teacher's Handbook.Zimbabwe Open University.Harare,Zimbawe

[6]. Chitiyo,M \&Wheeler,J (2004) The Development of Special Education Services in Zimbabwe.International Journal of Special Education 2004,Vol 19,No .2 (Online).Available url:www.internationalsped.com/documents/chitiyo\%20zimbabwe\%20(6).doc Accesed on 26/04/2012

[7]. Choruma,T (2007).The forgotten tribe:People with Disabilities in Zimbabwe.(Online).Available url:htt://www.sarpn.org.za/documents/d0002847/index.php.Accessed on 16/04/2012.

[8]. Denscombe,M (2010), The Good Research Guide for Small- scale social research projects.Open University Press.McGraw-Hill Education

[9]. Donaldson,T (2005) Report on the issue of url:http://www.headwaterscommunities.ca/documents/ReportonInclusion.pdf Accessed on 16/04/2012

[10]. Fennick.E \& Liddy,D (2001) “Responsilibilities and Preparation for Collaborative Teaching:Co- Teacher's Perspectives”.Teacher Education and Special Education,24,3,229-240.

[11]. Guralnick,M.J (2001)' A Framework For Change in Early Childhood Inclusion'In M.J.Guralnick (ed) Early Childhood Inclusion;Focus on Change.Baltimore: Paul H.Brookes Publishing Company.

[12]. Hall,R,Campher,E \& Smit,A.G(2004)' Formal Support In Inclusion' In P.Engelbrecht.L.Green,S.Naiker and I Engelbrecht (eds) Inclusive Education in Action in South Africa.Pretoria:Van Schaik Publishers.

[13]. Hasting,R.P \& Oakford,S (2003) Student Teacher's Attitudes towards the Inclusion of Children with Special Needs.EducationL Psychology,23(1):87-94. 
[14]. Irish Department of Education (2007)Inclusion of Students with Special needs Post-Primary Guidelines.Online Availabe url:http:// www.sess.ie/sites/default/files/insp-inclusion-studen...Accessed on 27/08/2012

[15]. Kaplan,I (2007) “Inclusive School Design :Lombok,Indonnesia”,in EENET Asia Newsletter No 4,Jakarta,Indonesia:EENERT Asia,pp.18-19.

[16]. Kristen,K.\& Omagar-Loican,M (2007) Towards Inclusive Education: A case from Uganda.Online Available url:http://www.ajol.infor/index.php/saje/article/viewFile/69820/57901. Accessed 20/05/2012

[17]. Lang,R.\& Charowa,G (2005) DFID SCOPING STUDY:DISABILITY ISSUES IN ZIMBABWE.Online Available url:http;//.www.dcdd.nl/data/1213686448155- DFID\%20Disability\%Scoping\%20Study\%20Zimbabwe.pdf $\quad$ Accessed on 23/04/2012

[18]. Leedy,P.d.,\& Ormond,J.E (2005) Practical research: Planning and Design, $\left(6^{\mathrm{TH}}\right.$ Edition).New Jersey.Pearson Merill Prentice Hall.

[19]. Leornad Cheshire Disability (2012) Inclusive Education.Online Available url:http://www.leonard Cheshire.org.zw/programmes.html Accesed on 01/04/12

[20]. Mendy,N.A (2011) Inclusion of Blind and low Vision Children in Regular Schools in the Gambia.Online Available url:www.african.org/Ghana/Nancy.doc

[21]. Metts,R (2004) Disability and Available url:http:siteresources.worldbank.org/DISABILITY/Resources/280658-1172609074/metts BGpaper.pdf Accessed 13/04/2012.

[22]. Miles,S \& Singal,N (2008)The Education for All and Inclusive Education debate: Conflict,contradiction or opportunity? Online.Available url: http://www.leeds.ac.uk/disability studies/archiveuk/miles/IJIE-Miles andSingal-resubmission.df Accessed on $30 / 04 / 2012$

[23]. MacCathy,K (2006) Full Inclusion:The benefits and Disadvantages of Inclusive Schooling An Overview.Online Available url:http://www.eric.ed.gov/ERICWebPortal/recordDetail?accno=ED49 Accessed on 23/10/2012

[24]. McNabb,C (2011) Descriptive Research Mothodologies.Online Available url:http://pangea.tec.selu.edu/cmcnabb/philosop/power.ppt-120k Accsessed on 30/09/2012

[25]. Mutepfa,M.M,Mpofu,E \& Chataika,T (2007) Inclusive Education in Zimbabwe:policy,curriculum,practice,family,and teacher education issues.Online Available url:http://www.thefreelibrary.com/Inclusive+education+in+Zimbabwe\%A+POLICY,+curriculum,+practice,_.._a0168163364 Accesed on 26/04/2012

[26]. National Association for the Education of Young (2000) The Benefits of an Inclusive Education:Making It Work Online Available url:Childre.http://www.kidsource.com/content3/Inclusion.p.k12.3 html Accessed on 25/04/2012

[27]. Nevada partnership in Inclusive Education (2011) The Promise of Inclusive Education.Online.Available url:http://nvpie.org/inclusive.html

[28]. Parasuram,K (2006) Variables that affect teacher's attitudes towards disability and Inclusive education in Mumbai,India.Disability and Society,21(3):231-242

[29]. Peresuh,M.,\& Barcham,L (1998)Special Education Provision In Zimbabwe. British Journal of Special Education,Vol.25,No.2

[30]. Peters,S.J (2004)Inclusive Education: An EFA Strategy for All Children. Online Available url:http://siteresources.worldbank.org/EDUCATION/Resources/278200-1099079877269/5476641099079993288/InclusiveEdu efa strategy for children.df Accessed on 23/05/12

[31]. Scotland Education Deartment (2004) Focusing on Inclusion and the Education (Additional Support for Learning)Online Available url: http://www.educationscotland.gov.uk/images/Focusing OnInclusion tcm4-342924.pd Accessed on 14/09/12

[32]. Sierra,H.T.A \&Towell,D (2011) Advancing Inclusive Education for an Inclusive Society:Reflections on a journey in Latin America,Spring,2011

[33]. Torrenno,S (2011) Five Barriers in Education.Online Available url:http://www.brighthub.com/education/special/articles/68827.aspx $24 / 08 / 12$

[34]. Trochim,M,K.W (2006) Descriptive Statistics Online Available url:http:www.socialresearchmethods.net/kb/statdesc.php Accessed 20/09/2012

[35]. Turnbull,A Turnbull,R.,Wehmeyer,M.L (2006) Exceptional lives:Special education in today's schools (5 ${ }^{\text {th }}$ ed.) New Jersey:Merill Prentice Hall.

[36]. Robson,C (2002) Real World Research:A resource for Social Scientists and Practitioner-Researcherss.Oxford.Blackwell Publishers Ltd.

[37]. United Nations Educational,Scientific and Cultral Organisation (UNESCO)(2005) Guidelines for Inclusion:Ensuring Access to Education for All (Theoretical Framework). Composed and Printed in the workshops of UNESCO@ UNESCO 2005. Online Available url:http://unesdoc.unesco.org/images/001402.1402402/140224e.pdf 23/03/2012

[38]. UNESCO (2008) International Conference On Education: National Report on the Status of Education by Zimbabwe.Online Available url:http://www.ibe.unesco.org/National_Reports/ICE_2008/zimbabwe_NR08.pdf Accesed on 27/09/12

[39]. UNESCO (2009) Teaching Children with Disabilities in Inclusive Setting.Online Available url:http://unesdoc.unesco.org/images/0018/001829/18297e.df Accessed on 24/06/12

[40]. United Nations Educational,Scientific and Cultural Organisation (UNESCO) (2003b) Overcoming Exclusion through Inclusive Approaches in Education.A challenge and a vision.Paris,UNESCO.

[41]. United Nations (2006) Convention on the Rights of Persons with Disabilities-Article 2.New York: United Nations Online Available url:http:// www.un.org/disabilities/conventionfulkl.shtml Accessed 27/07/12

[42]. United Nations (UN) (2002).Human Rights A Compilation of International Instruments, Volume 1 (First Part) Universal Instruments.United Nations,New York \& Geneva

[43]. Wiersma,W.\& Jurs,S (2005) The Research Methods in Education: An Introduction.USA.Pearson Education,Incl. 